\title{
Reference Librarians and LIS Students: Contrasting Views of Reference Source Training and Experience
}

\begin{abstract}
An examination of students' and practitioners' attitudes towards, and uses of, various reference sources. Students found print sources to be educational, but use of print is waning. Many practitioners said learning specific sources was best done on the job, and felt new hires were better prepared to use online sources.
\end{abstract}

\section{Introduction}

Our conception of the use of physical space in libraries, and especially the reference area, has undergone a fundamental change in recent years. Where books previously made a large footprint in the reference section, many libraries have shifted to "people space"--creating areas for group work, computers, or common space for study and socializing (Wolfe, Naylor and Druecke, 2010). Some libraries have almost completely shifted to an online format for their reference sources, using a combination of subscription databases and free Internet sources. Reference models have made use of the shift to online access, as well--online reference (such as chat) has become increasingly common, placing more importance still on online sources (Tyckoson, 2011). However, this research found that reference work is often still done in a traditional manner, with print sources and live people.

Because of the changing reference environment, there have been several recent studies that have discussed the issue of education for future reference librarians--what should we be teaching our students in the classroom in order to help them get jobs, and make contributions to the field? Adkins and Erdelez (2006) surveyed reference instructors to determine how they divide their instruction between print and online reference sources. O'Connor (2011) examined syllabi of reference classes in order to determine whether changes in practice are reflected in LIS education. This research began as a pedagogical problem--how to teach, or whether to teach, print resources in this new reference landscape, using a new pedagogical model (from in-person to largely online). We quickly realized, though, that the underlying issue goes beyond which sources to teach, to what was most important for students to learn in class and what they needed to know on the job. This study, therefore, was conducted in order to gain the viewpoints of multiple groups of stakeholders whose views had not been recorded.

Reviewing the literature, we found no studies that systematically examine practitioners' opinions about student preparation, nor any studies regarding students' impressions of course requirements. (We did, of course, find anecdotal accounts on the inappropriateness of LIS education and its lack of connection to the profession, notably in blogs). Most analysis of the reference curriculum has been done by LIS educators. If educators want to meaningfully examine their course requirements, it 
makes sense to look outside of education, toward students and their future employers. The model below indicates the directions of analysis already done and yet to be done.

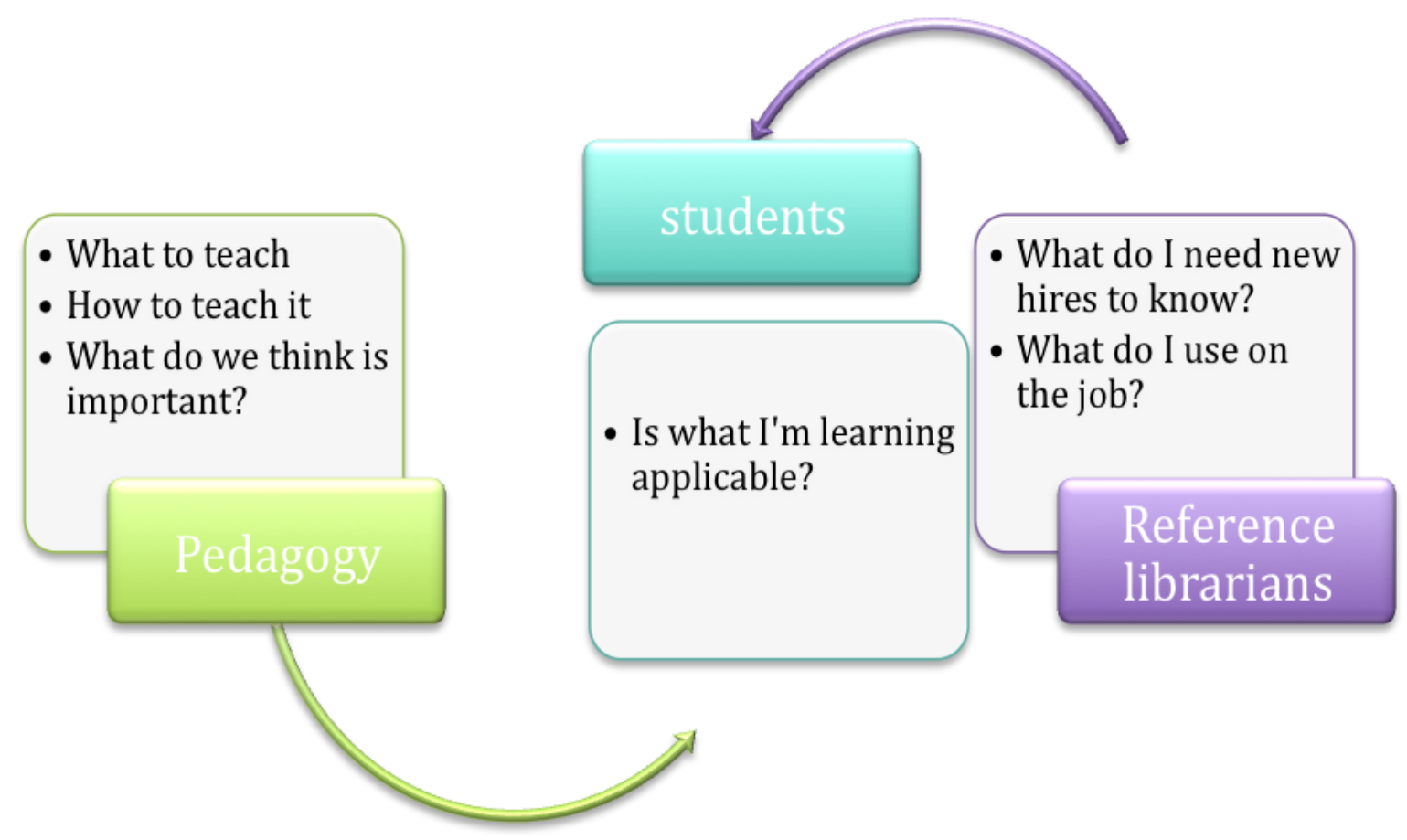

This study seeks to fill the gaps in the literature by discovering how students perceived the usefulness of requirements in an introductory reference class, whether the requirements met the needs of their future employers, and whether their expectations from the class reflected the reality of librarianship. The first survey was directed towards students, asking whether they thought assignments requiring them to use various print resources were useful or whether the assignments caused them undue hardships. The second survey was directed at practitioners, aiming to find out what they wanted new hires to know. Looking at these surveys together, we hope to find out if there are some commonalities amongst the wide variety of libraries that we, as library educators, serve. What skills and traits should new librarians possess? What can they learn in school, and what must they learn on the job?

\section{Method}

This exploratory study sought to gauge perceptions of students and librarians regarding education for the profession in reference, and to determine whether these concepts were appropriate to measure with survey-type instruments. Surveys for practitioners and students were developed and pretested with the appropriate audiences. After these pretests, both surveys were distributed via a web-based survey platform. Both surveys were primarily quantitative with closed-ended questions asking for ranking or yes/no answers. However, many questions asked for clarification on why the respondents answered as they did.

The first survey was distributed via email to 95 students at two different ALAaccredited LIS programs. This was a convenience sample based on professional 
contacts the authors had at those institutions. We received 78 responses, for an $82 \%$ response rate. All of the students were taught reference in an online environment. Fifteen of the students were undergraduates; the rest were students in the Master's program. The 26-question student survey asked about their previous experience with reference sources and feelings about their reference instruction and assignments. While the classes were taught at two different universities, both required students to look up answers in reference sources (fact-finding). Furthermore, all students were required to use print resources, necessitating trips to libraries' reference sections.

The second survey was directed at practitioners. This survey aimed to provide a more critical view, questioning how employers and colleagues in libraries perceive the reference skills of new hires who had recently completed their school work. Fliers were distributed via registration packets at two state library association conferences, and the authors attended these conferences to answer questions about the survey there. The survey had two foci: the librarians' reference practice, and how they regard the skill sets of new hires. Questions regarding their own practice included what reference sources and types they used and what sort of reference model was used at their library. Questions about new hires asked practicing librarians to assess the skills that new hires brought to the reference environment, and whether those new hires are adequately trained.

All research has weaknesses, and this is no exception. Because of the online nature of the survey, we were unable to gauge the sample size that the survey would have reached, and we also had less control over who responded to the survey. While we had indicated that the survey was directed toward reference practitioners, we did get some respondents who worked in administration or other library areas. Further, the trade-off in using survey methodology is essentially quantity in lieu of quality. Because we did use a survey methodology, our respondents may not have been able to respond as fully and completely as they might have in interviews. Our convenience sample also limits the generalizability of this research, as the views and issues that were shared with us may not reflect the greater reality of North American reference services.

\section{Findings}

Respondents to the student survey were generally positive about their learning experiences and their opportunities to work with print and electronic reference sources. Most of the students felt that they were learning a lot of new things and were pleased that they had been required to use both print and electronic reference sources in their reference class. Many thought that the assignments involving print resources helped them understand the nature of reference work, how they might go about finding the best information, and about how reference sources are organized.

Many of the student respondents had not worked in libraries (at least in the reference section), and the assignments gave them an opportunity to develop their reference skills in the library context, even talking to librarians about how they might go about finding their answers. But because they had not worked as reference librarians, their feelings of satisfaction or dissatisfaction with the curriculum were, in many ways, divorced from the context that reference work would otherwise provide. 
Forty-four practitioners responded to our second survey. Of those, 31 were from public libraries, 12 from academic libraries, and one person was from a school library. Half of the academic library respondents indicated that their library served between 1000 and 5000 students, while $44 \%$ of public library respondents said their libraries served populations between 100,000 and 500,000. Respondents were evenly distributed in years of service, with $34 \%$ having been hired in 2000 or later and $41 \%$ hired before 2000. (The remainder did not answer this question.)

Respondents reported that the majority of their interactions with patrons were either in person or on the telephone. Chat, video chat, and e-mail interactions were not as customary. They rarely do in-depth research consultation, spending most of their time on technology issues (printers, applications, etc.) and answering factual questions. When they were asked to rate which sources they most often used, most said that online subscription services were the most important source, and print was secondmost important. Free sources were least important.

What do practitioners look for in new hires? A majority believe that students are adequately trained in using print sources (53\%) and electronic sources (77\%), most practicing reference librarians felt that new hires did not know the best sources to answer reference questions. This was viewed as a skill that would come with additional on-the-job experience and familiarity with the library's unique collection. One comment, typical of several others, was, "So much of what we do and how we answer questions has to do with what is unique to a particular collection and the patron or patron group being served. In the beginning sometimes these are not apparent because this is a learned skill set."

Several practitioners' comments portrayed print as either a dying source or an ignored source. Comments from practicing librarians indicated that print sources were used less frequently in libraries, and that they appeared to be taught less frequently as well. However, the student survey indicated that students seemed to feel that they benefited from using print resources, as well as from perusing the physical reference collection. For example, one student said, "The catalog search for an appropriate reference coupled with the actual exploration of the source for an answer was vital. I also learned a lot from asking questions at the reference desk and seeing how professionals tackled the questions." Many students enjoyed seeing how reference professionals worked in situ, and the interaction between the students and the professionals was fruitful for the students' professional development.

Although practitioners had more confidence in students' ability to use electronic rather than print resources, they acknowledged that using sources on the job was necessary to developing a fuller understanding. "Much of this experience comes from on the job training.... Artificial scenarios don't always replace the real reference interactions." Students did feel that what they learned in class regarding databases was invaluable: "Being exposed to many of those [proprietary databases] that I was not using before has really changed my approach to research." Google received positive and negative reviews among the practicing librarians. While one commenter suggested that "the world is attached to Google," another said, disparagingly, that it was the first 'source' new hires always turn to.

Several practitioners mentioned "other" skills: persistence, cooperation, and the 
ability to understand what a patron is looking for. In the ratings, $100 \%$ of respondents said it was "very important" for new hires to have good interpersonal skills. This tends to confirm other research about the importance of librarians' communication skills. One of our respondents expressed her sense that online education was failing the profession in this regard. Since so many students are taking online courses, she felt they were not adequately prepared to communicate with patrons.

\section{Discussion}

While research has been conducted on library education, it tends to focus on the process of education, rather than the product. This research fills a gap in the professional literature by including students' and practitioners' points of view in regard to reference education and training. Rather than focusing exclusively on the educator's domain, this study looks outward to the field and educators' impact thereon.

Ideas about reference seem to be changing, from print-focused to electronicallyoriented, but not as quickly as we might think. Many librarians reported that they still use, and expect other librarians to use, a variety of print sources. Most of their interactions with patrons occurs face-to-face, and they expect new hires to be able to work well with patrons in this way, not simply turning to Google for an answer. Students were relatively consistent about the importance of learning print sources, but there was little consistency among practicing librarians who responded to the survey regarding what sources students should be able to use. Students mention convenience as a major factor in their use of sources during reference class, but also indicate the need for the interpersonal interaction that they had at the library.

The reference model is in flux, and this will necessarily change our conceptions of how to teach reference and how students best can learn to use reference sources. This study should be repeated on a larger scale, to gather a consensus as to what sources are particularly valued but also what types of education are more or less effective for the purposes of library practice. Students from face-to-face and hybrid classes should be surveyed to determine whether they have different perceptions from online students as to the usefulness of their coursework and the connections made with library staff.

Most (70\%) of the practitioners who responded to the survey worked in public libraries, reflecting attendance at the library association meetings. An attempt must be made to include the views of academic librarians. In our conversation with librarians about this survey, some suggested that reference service in academic and public libraries is diverging. This may lead to different expectations of new hires, and may demand different types of reference instruction based on library type. 